\title{
Operation of Induction Motor-Drive under Different Voltage Sag Conditions
}

\author{
A. Farahbakhsh, A. Jalilian \\ Department of Electrical Engineering \\ Iran University of Science \& Technology, \\ Farjam st., Narmak, Tehran, Iran. \\ jalilian@iust.ac.ir
}

\begin{abstract}
Simulation of an Induction Motor-Drive system under various voltage sag conditions using Matlab/Simulink is presented in this paper. Variation of input current, speed and output torque for induction motor-drive is investigated in this paper. Simulation results show that the variation of speed and current in motor-drive system basically depends on the size of the dc link capacitor. It is shown that the maximum reduction of dc-link voltage happens during voltage sag type A. Unsymmetrical VS types $\mathrm{E}$ and $\mathrm{G}$ cause the maximum reduction and type $\mathrm{B}$ causes the minimum reduction of dc-link voltage respectively. The reduction of dc-link voltage depends to dc-link and source inductances. The higher reduction in dc-link voltage is resulted when the larger inductance is used.
\end{abstract}

Keywords: DC-link, inverter, induction machine, IM-drive, voltage sag.

\section{Introduction}

Reduction in rms supply voltage between 0.1 and 0.9 p.u. with duration of 0.5 cycle to $1 \mathrm{~min}$ is called voltage sag (dip) [1]. Because of the advantages of IMs (such as high speed, simplicity of maintenance, wide variation of speed), they have become more common in the industries. By developing power electronic, microcomputer technology and new control techniques, the usage of drives are promoted to supply IMs [2].

PQ problems affecting IM performance are harmonics, voltage unbalance, voltage sags, interruption etc. Voltage sag is one of the most frequent $\mathrm{PQ}$ events which are common in recent distribution systems [2,3]. The behavior of IM under different voltage sag conditions is studied using simulation of an IM in Matlab environment [4]. Transient behavior of IMs is also studied where it is shown that the motor performance depends on the sag magnitude, duration, motor loading level and mechanical inertia [5, 6].

Operation of motor-drive systems are also affected while voltage sag happens in a system [7]. In addition to speed loss (slip variation), voltage sag could result in a high onsag, post-sag currents and torque peak. Sudden and sharp variation of current may cause triggering of protection system. Diverse torque peaks during motor's life time can weaken motor's shaft and variations of speed damage the final product in different applications. So to study the operation of IM-drive under different voltage sag conditions, the variation of these three parameters are very important.

In this paper first, various types of voltage sag are simulated in Matlab/Simulink environment. Thereafter, performance of an IM-drive system is simulated and the results are analyzed in order to identify the parameters affecting the drive-motor performance. Finally, by solving the current equations the impact of dc link voltage variations and supply inductance is also investigated in this paper.

\section{Simulation of voltage source}

Due to different kinds of faults in power systems, different types of voltage sag can be produced. Different types of transformer connections in power grid have a significant role in determination of voltage sag type [6]. Voltage sag are divided in to seven groups as type A, B, C, D, E, F and G as shown in table (1). In this table " $h$ " indicates the sag magnitude. Type A is symmetrical and the other types are known as unsymmetrical voltage sag.

Table 1 The equations of different voltage sags [8]

\begin{tabular}{|c|c|}
\hline Type A & Type B \\
\hline$V_{a}=h V$ & $V_{a}=h V$ \\
\hline$V_{b}=-\frac{1}{2} h V-\frac{1}{2} j h V \sqrt{3}$ & $V_{b}=-\frac{1}{2} V-\frac{1}{2} j V \sqrt{3}$ \\
\hline$V_{c}=-\frac{1}{2} h V+\frac{1}{2} j h V \sqrt{3}$ & $V_{c}=-\frac{1}{2} V+\frac{1}{2} j V \sqrt{3}$ \\
\hline Type C & Type D \\
\hline$V_{a}=V$ & $V_{a}=h V$ \\
\hline$V_{b}=-\frac{1}{2} V-\frac{1}{2} j h V \sqrt{3}$ & $V_{b}=-\frac{1}{2} h V-\frac{1}{2} j V \sqrt{3}$ \\
\hline$V_{c}=-\frac{1}{2} V+\frac{1}{2} j h V \sqrt{3}$ & $V_{c}=-\frac{1}{2} h V+\frac{1}{0} j V \sqrt{3}$ \\
\hline Type E & Type F \\
\hline$V_{a}=V$ & $V_{a}=h V$ \\
\hline$V_{b}=-\frac{1}{2} h V-\frac{1}{2} j h V \sqrt{3}$ & $V_{b}=-\frac{1}{3} j V \sqrt{3}-\frac{1}{2} h V-\frac{1}{6} j h V \sqrt{3}$ \\
\hline$V_{c}=-\frac{1}{2} h V+\frac{1}{2} j h V \sqrt{3}$ & $V_{c}=+\frac{1}{3} j V \sqrt{3}-\frac{1}{2} h V+\frac{1}{6} j h V \sqrt{3}$ \\
\hline Type G & Where $0 \leq h<1$ \\
\hline$V_{a}=\left(\frac{2}{3}+\frac{h}{3}\right) V$ & ( $h:$ Sag magnitude) \\
\hline$V_{b}=-\frac{1}{6}(2+h) V-\frac{1}{2} h V j \sqrt{3}$ & \\
\hline$V_{c}=-\frac{1}{6}(2+h) V+\frac{1}{2} h V j \sqrt{3}$ & \\
\hline
\end{tabular}




\section{Simulation of IM-drive}

Simulation of the IM-drive system is performed in Matlab/Simulink and SimPower environments. Voltage sags of types A- G, produced by software, are applied to the test system. Schematic diagram of the simulated system is shown in Fig. 1.

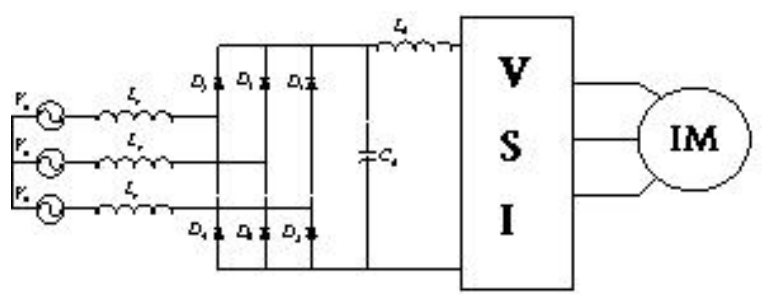

Fig. 1. An IM-Drive with a diode converter, a dc-link capacitor, a voltage source inverter and an IM

The drive system consists of six diodes, a dc link capacitor $\left(\mathrm{C}_{\mathrm{d}}\right)$ and a dc link inductance $\left(\mathrm{L}_{\mathrm{d}}\right)$. The source inductance $\left(\mathrm{L}_{\mathrm{s}}\right)$ is also considered for simulation purposes. Voltage sag depth and duration are two major factors which their effects are considered on motor-drive performance. The size of $\mathrm{dc}$ link capacitor and the motor loading level are changed in simulation and their effects on IM-drive system are studied. In order to achieve more realistic results, the actual modeling of diodes and IGBTs are employed in simulation. Two size for capacitor is chosen $(100 \mu F$ and $1 \mathrm{mF})$.

\subsection{Simulation Results}

The operation of IM-drive is studied under a voltage sag with duration of $0.2 \mathrm{~s}$ (it started at $\mathrm{t}_{\mathrm{on}-\mathrm{sag}}=0.5 \mathrm{~s}$ and stopped at $\left.\mathrm{t}_{\text {post-sag }}=0.7 \mathrm{~s}\right)$ and magnitude of $90 \%(\mathrm{~h}=10 \%)$.

The voltage waveforms and positive/negative sequence voltage components for an unsymmetrical type (such as type B) are shown in Fig. 2.

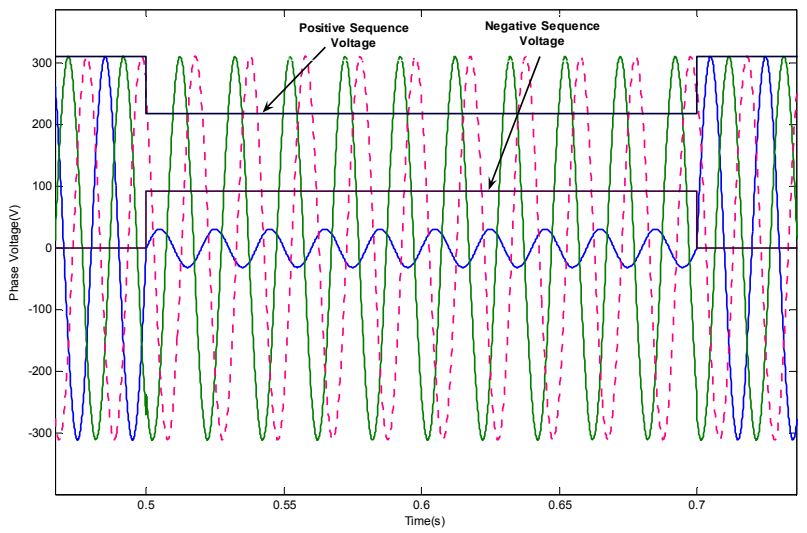

Fig. 2. Voltage waveforms and positive/negative sequence components for an unsymmetrical voltage sag $(\mathrm{h}=10 \%)$
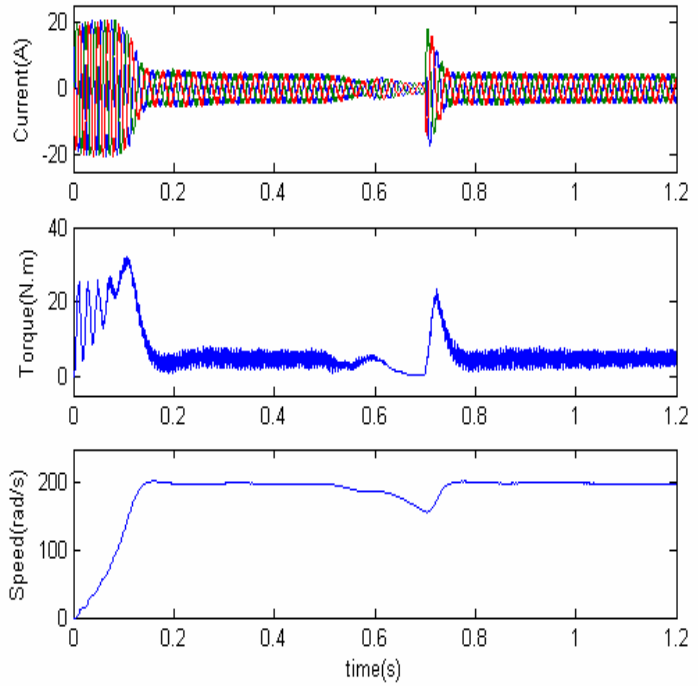

Fig. 3. Variation of current, torque and speed during voltage sag type $\mathrm{A}(\mathrm{h}=10 \%, \mathrm{t}=0.2 \mathrm{~s})$ and $\mathrm{C}=1 \mathrm{mF}$

Because of the inverter switching, the output voltage contains ripples, so the output currents and the produced torque have ripples too. The waveform of currents, torque and speed of induction motor under $50 \%$ full load for voltage sag type $\mathrm{A}(\mathrm{h}=10 \%)$ are shown in Fig. 3.

Different types of voltage sag are applied to the IM-drive system. Summary of simulation results are presented in Table 2 to compare the current and torque peaks and speed loss.

Table 2 - Variation of current, torque peak, dc link voltage and speed loss under VS conditions

\begin{tabular}{|c|c|c|c|c|}
\hline $\begin{array}{c}\text { Voltage } \\
\text { sag type }\end{array}$ & $\begin{array}{c}\text { Current } \\
\text { peak } \\
(\%)\end{array}$ & $\begin{array}{c}\text { DC-link } \\
\text { voltage } \\
\text { reduction(\%) }\end{array}$ & $\begin{array}{c}\text { Torque } \\
\text { peak } \\
(\%)\end{array}$ & $\begin{array}{c}\text { Speed } \\
\text { loss } \\
(\%)\end{array}$ \\
\hline $\mathrm{A}^{*}$ & $45 \%$ & $90 \%$ & $60 \%$ & $45 \%$ \\
\hline $\mathrm{B}$ & $60 \%$ & $40 \%$ & $100 \%$ & $2.5 \%$ \\
\hline $\mathrm{B}^{*}$ & - & $5 \%$ & - & - \\
\hline $\mathrm{C}$ & $80 \%$ & $35 \%$ & $50 \%$ & $5 \%$ \\
\hline $\mathrm{C}^{*}$ & $20 \%$ & $15 \%$ & $40 \%$ & $2.5 \%$ \\
\hline $\mathrm{D}$ & $35 \%$ & $25 \%$ & $130 \%$ & $4 \%$ \\
\hline $\mathrm{D}^{*}$ & $10 \%$ & $5 \%$ & $60 \%$ & $2 \%$ \\
\hline $\mathrm{E}$ & \multicolumn{5}{|c|}{ Motor stops } \\
\hline $\mathrm{E}^{*}$ & $100 \%$ & $40 \%$ & $90 \%$ & $7 \%$ \\
\hline $\mathrm{F}$ & \multicolumn{5}{|c|}{ Motor stop } \\
\hline $\mathrm{F}^{*}$ & $60 \%$ & $33 \%$ & $90 \%$ & $5 \%$ \\
\hline $\mathrm{G}$ & \multicolumn{5}{|c|}{ Motor stops } \\
\hline $\mathrm{G}^{*}$ & $100 \%$ & $42 \%$ & $90 \%$ & $7 \%$ \\
\hline
\end{tabular}

Simulation results show that the values of currents and torque peak depend on the $\mathrm{dc}$ link capacitance. The maximum reduction of dc-link voltage is under voltage sag type $A$ and for unbalance types it happens for type $E$ and $G$ respectively. The maximum current peak happens under voltage sag type $\mathrm{E}$. Types $\mathrm{E}$ and $\mathrm{G}$ cause the maximum speed loss among unbalance voltage sags. 


\section{Variation of dc-link voltage under different VSs}

Variations of dc-link voltage under different types of VSs with different amplitude for two sizes of capacitors are presented in Fig. 4 and Fig. 5.

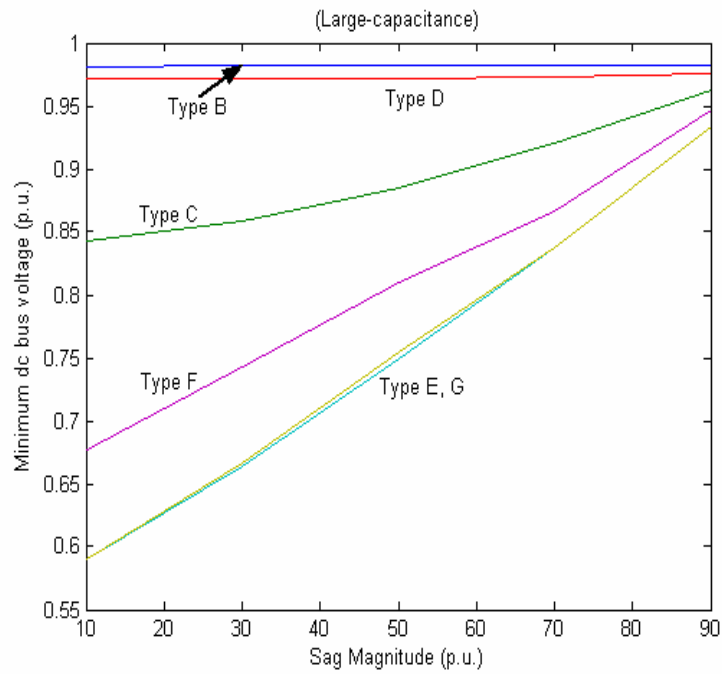

Fig 4: Variation of dc-link voltage under different VSs $(\mathrm{C}=1 \mathrm{mF})$

Comparing the simulation results show that for $\mathrm{C}=1 \mathrm{mF}$ the maximum reduction occurs during type $F$ and $G$ and the minimum reduction occurs for types $\mathrm{B}$ and $\mathrm{D}$. For large capacitors, the variation for type $\mathrm{B}$ and type $\mathrm{D}$ are almost the same. For small capacitors $(100 \mu F)$, the variation of voltage are closer to each other rather than large capacitor.

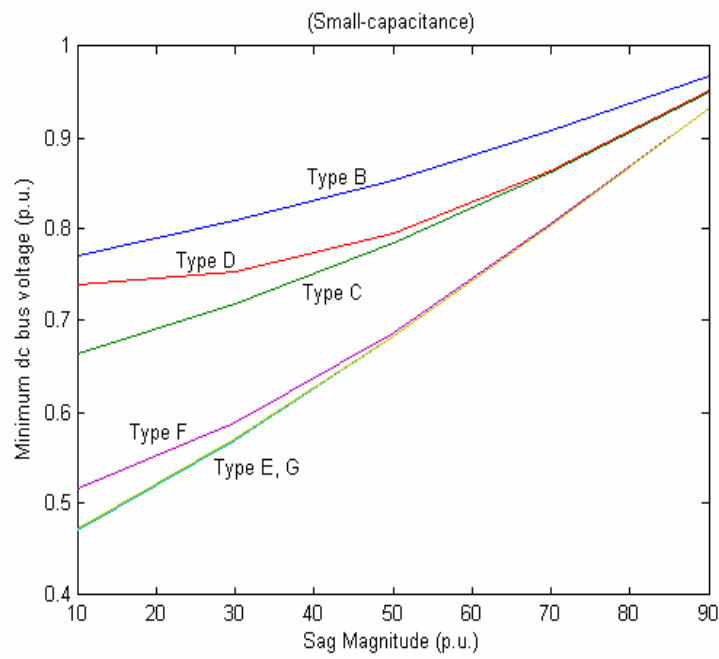

Fig. 5: Variation of dc-link voltage under different VSs $(\mathrm{C}=100 \mu F)$

\section{Effects of source impedance on IM-drive operation} Analytical calculation is done to investigate the effect of source inductance on IM-drive for one phase fault.

The dc equivalent circuit is shown in Fig. 6. The effective inductance $\left(\mathrm{L}_{\mathrm{eff}}=2 \mathrm{~L}_{\mathrm{s}}+\mathrm{L}_{\mathrm{d}}\right)$ is in series with source and dclink capacitance.

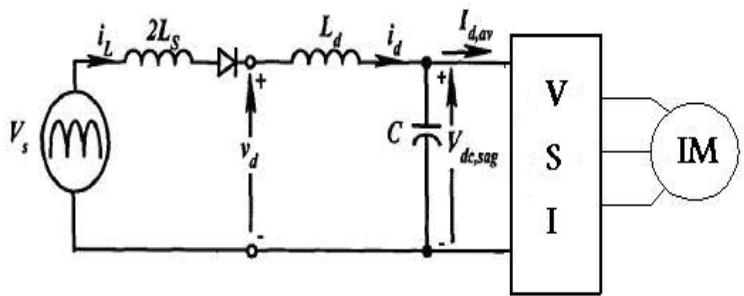

Fig. 6: equivalent circuit to study the effect of source and dc-link inductances

\subsection{Analytical calculation}

To investigate the effects of source impedance, the equation which is presented in [7] is solved and the variation of output power for different voltage levels are calculated and presented in Figs 7 and 8.

The equations show that dc-link voltage depends on output power $\left(\mathrm{P}_{\mathrm{o}}\right)$ and effective inductance $\left(\mathrm{L}_{\mathrm{eff}}\right)$. By increasing the values of $L_{s}$ and $L_{d}$, the dc-link voltage decreases more, so the drive will be more vulnerable against VS. In Fig. 8 the variation of dc-link voltage for $\mathrm{L}_{\mathrm{d}}=0 \%$ and $\mathrm{L}_{\mathrm{s}}=1-10 \%$ is shown.

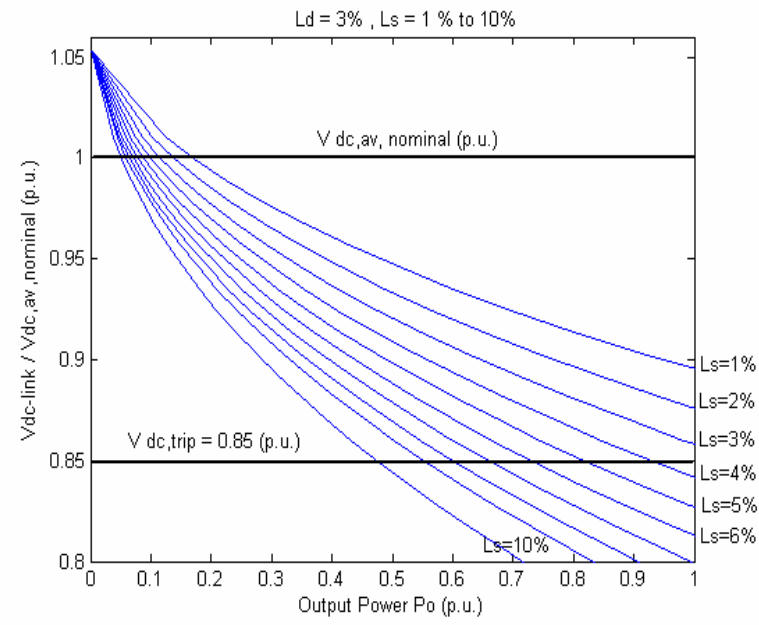

Fig. 7: Variation of dc-link voltage with source and dclink impedance $L_{s}=1-10 \%, L_{d}=3 \%$ 


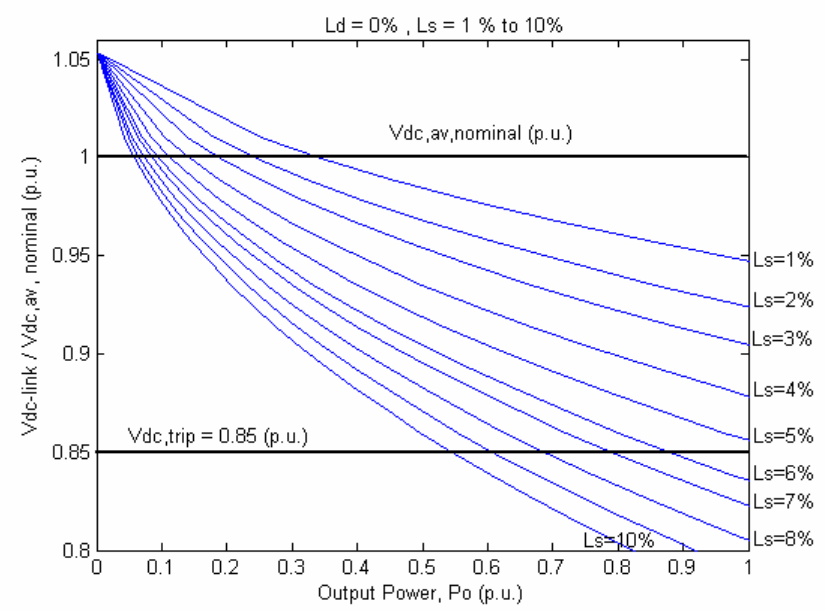

Fig. 8: Variation of dc-link with source and dc-link impedances $\left(L_{s}=1-10 \%, L_{d}=0 \%\right)$

Simulation of a case study is introduced in this section to illustrate the effects of these parameters more clearly. A $22 \mathrm{kVA}, 60 \mathrm{~Hz}, 480 \mathrm{~V}$ drive is used for simulation purposes. The simulation results are shown in Table 3. The variation of dc-link voltage for different output powers and different $\mathrm{L}_{\mathrm{d}}$ and $\mathrm{L}_{\mathrm{s}}$ are shown. It can be seen that for $\mathrm{L}_{\mathrm{s}}=5 \%$ and $\mathrm{L}_{\mathrm{d}}=3 \%$ the dc-link voltage reduces to $536 \mathrm{~V}$ which is under $\mathrm{V}_{\mathrm{dc} \text {,trip }}$, so the under voltage trip happens. With reduction of values of the $L_{d}$ and $L_{s}$ the dc-link voltage level becomes higher.

Table 3: Dc-link voltage variation for different loading levels

\begin{tabular}{|c|c|c|c|c|}
\hline Description & $\begin{array}{c}\text { DC-link } \\
\text { Voltage } \\
(\mathbf{V})\end{array}$ & $\begin{array}{c}\text { Loading } \\
\text { level } \\
(\%)\end{array}$ & $\mathbf{L}_{\mathbf{d}}(\boldsymbol{\%})$ & $\mathbf{L}_{\mathbf{s}}(\boldsymbol{\%})$ \\
\hline $\begin{array}{c}\text { Normal } \\
\text { Operation }\end{array}$ & 585 & $50 \%$ & $3 \%$ & $5 \%$ \\
\hline $\begin{array}{c}\text { Under Voltage } \\
\text { Trip }\end{array}$ & 536 & $100 \%$ & $3 \%$ & $5 \%$ \\
\hline $\begin{array}{c}\text { Normal } \\
\text { Operation }\end{array}$ & 592 & $100 \%$ & $0 \%$ & $3 \%$ \\
\hline $\begin{array}{c}\text { Under Voltage } \\
\text { Trip }\end{array}$ & 539 & $70 \%$ & $0 \%$ & $8 \%$ \\
\hline $\mathrm{V}_{\mathrm{dc}, \text { av,nominal }}=650 \mathrm{~V}, \mathrm{~V}_{\mathrm{dc}, \text { trip }}=553 \mathrm{~V}, \mathrm{~V}_{\mathrm{LN}}=277 \mathrm{~V}$, \\
$\mathrm{PF}=0.68$
\end{tabular}

\section{Conclusion}

The behavior of IM-Drives under different voltage sag (VS) conditions is investigated in this paper using Matlab. Different types of VSs are produced and applied to IMDrive system model under different loading levels. The variation of motor's current, speed and output torque are analyzed during and after clearing voltage sags. It is demonstrated that the increasing of the dc-link capacitor size mitigates the effect of VS on IM-Drive. The maximum reduction of dc-link voltage happens during voltage sag type A. For unsymmetrical types, $\mathrm{E}$ and $\mathrm{G}$ cause the maximum reduction and type $\mathrm{B}$ causes the minimum reduction of $\mathrm{dc}$ link voltage. The reduction of dc-link voltage depends to dclink and source inductance $\left(\mathrm{L}_{\mathrm{d}} \& \mathrm{~L}_{\mathrm{s}}\right)$. The higher the inductance the lower the dc-link voltage is resulted.

\section{References}

[1]. R.C. Dugan, M. F. McGranaghan, H. W. Beaty, "Electrical Power Systems Quality", New York: McGraw-Hill, 1996.

[2]. Souto C. "Power Quality Impact on Performance and Associated Costs of Three-Phase Induction Motors", 8th International Conference on Harmonics and Quality of Power, Greece, October 1998.

[3]. J C. Gomez, M. Morcos, G N. Campetelli, "Behavior of Induction Motor Due to Voltage Sags and Short Interruptions", IEEE Transaction on Power Delivery, Vol.17, No.2, April 2002.

[4]. A. Farahbakhsh, A. Jalilian, "Induction Motor Behavior Under Different Voltage Sag Conditions", $8^{\text {th }}$ International Conference on Electrical Power Quality and Utilization (EPQU), Poland, 2005.

[5]. A. Leiria, P. Numes," Induction Motor Response to Voltage Dips", International Conference on Power System Transient, IPST 2003.

[6]. L. Guasch, F. Corcoles, J. Pedra," Effects of Symmetrical and Unsymmetrical Voltage Sags on Induction Machine", IEEE Transactions on Power Delivery, Vol. 19, No. 2, April 2004.

[7]. J. L. Duran-Gomez, P. N. Enjeti, "Effect of Voltage Sags on Adjustable Speed Drive: A Critical Evaluation and an Approach to Improve its Performance", Applied Power Electronics Conference, Vol. 2, pp.774-780, March 1999.

[8]. M. Bollen, "Understanding Power Quality Problems: Voltage Sags and Interruptions", New York: IEEE Press, 2000. 